Maurício Trentin *

\title{
Aleatoriedade como tecnologia especulativa 0 randômico como instrumento na arte e no design
}

Maurício Trentin é artista, designer, programador e pesquisador. Doutor em Poéticas Visuais (2017 - ECA/USP) . Mestre em Comunicação e Semiótica (2010 - PUC-SP). Graduado em Desenho Industrial/Mackenzie (1994). Especializações na SVA NY, NYFA, Parsons NY, Story/Storynomics e Virtual Spatial Systems Design _UDK, Germany (Berlin). Membro do CCSP, da ADP (Associação dos Designers de Produto), da ADG (Associação dos Designers Gráficos do Brasil) e do Núcleo Contemporâneo do MAM (Museu de Arte Moderna de São Paulo). Trabalhos publicados pelas Archive, Publicis Worldwide Review, pelos Anuários de Fontes Digitais Brasileiras da ADG e do Clube de Criação de São Paulo, pelas revistas Arquitetura e Urbanismo, ArqDesign, KAZA, Casa Vogue, Viver Bem e pelo jornal Folha de S.Paulo. Integrante do grupo Poéticas Digitais, expôs a projeção multimídia CUBO BRANCO na mostra Visualidade Nascente no centro cultural Maria Antônia, São Paulo.

<mauriciotrentin@usp.br >

ORCID: 0000-0002-0284-3285
Resumo $\mathrm{O}$ texto discute a atualização do papel da aleatoriedade em processos criativos (poiesis e práxis), tanto em campos específicos quanto nas fronteiras colapsadas e movediças entre arte, design e tecnologia.

Apresenta o dispositivo/código_Cubo Branco_exemplo de creative coding, obra criada utilizando parâmetros randômicos e por fim investiga exemplos artísticos, lógicos e tecnológicos enquanto possibilidades de se parametrizar o acaso como processo criativo.

Palavras chave Aleatoriedade, Arte, Design especulativo, Tecnologia . 
Randomness as speculative technology.

The random as an instrument in art and design.

\begin{abstract}
The text discusses the updating of the role of randomness in creative processes (poiesis and praxis), both in specific fields and in the collapsed and shifting boundaries between art, design and technology.

It presents a device / code_Cubo Branco_example of creative coding, an artwork created using random parameters and finally investigates artistic, logical and technological examples as possibilities to parameterize chance as a creative process.
\end{abstract}

Keywords Randomness, Art, Speculative design, Technology.

Aleatoriedad como tecnología especulativa.

Lo aleatorio como instrumento en el arte y el diseño.

Resumen El texto analiza la actualización del papel de la aleatoriedad en los procesos creativos (poiesis y praxis), tanto en campos específicos como en las fronteras colapsadas y cambiantes entre el arte, el diseño y la tecnología.

Presenta el dispositivo / código_Cubo Branco_ejemplo de codificación creativa, un trabajo creado utilizando parámetros aleatorios y finalmente investiga ejemplos artísticos, lógicos y tecnológicos como posibilidades para parametrizar el oportunidad como un proceso creativo.

Palabras clave Aleatoriedad, Arte, Diseño especulativo, Tecnología. 
Letting a thing coe, rather than creating it - no assertions, constructions, formulations, inventions, ideologies - in order to gain access to all that is genuine, richer, more alive : to what is beyond my understanding... Using chance is like painting Nature - but which chance event, out of all the countless possibilities?"

Gerhard Richter, em Statement de 1985, republicado em CHANCE, Documents of contemporary art.

\section{Aleatoriedade como instrumento}

Pensar em campos tão amplos e radicalmente fluídos como os campos da arte, da tecnologia e do design seria por si só tarefa complexa, mas pensar nas intersecções potenciais desses campos, em suas fronteiras por vezes fluídas e outras vezes colapsadas, de modo resumido, seria talvez impossível, certamente injusto. Injusto com a riqueza que os campos apresentam individualmente, mas ainda mais injusto com a riqueza fluida de suas sobreposições e arranjos potenciais.

Não me parece o caso de elencar vários exemplos reais de obras/ tecnologias/obras "tecnológicas"/objetos especulativos/dispositivos/ etc. Primeiro porque não se trata de criar uma pseudotaxonomia de dispositivos, segundo porque, possivelmente, o recorte também, seria injusto, parcial e lacunar.

o que procure aqui, já de saída reconhecendo os limites práticos do discurso amplo, diagramático e não específico, a respeito de arte, design e tecnologia, é discutir um parâmetro que me parece de extrema importância quando se fala em/de tecnologia (como ferramenta, linguagem, assunto ou técnica) usada de modo especulativo e da intersecção de campos criativos, e da atualização tecnológica, poética e prática desses mesmos campos: a aleatoriedade.

Desde "How to make a dadaist poem" de 1920, com Tzara e em textos de outros dadaístas, a arte flerta com o randômico, com o acidental, com o descontrole e o acaso.

Talvez mesmo antes dessa data, e certamente depois, sejam acidentes provocados deliberadamente, ou com o aproveitamento de felizes acidentes de percurso, a arte e os artistas conhecem a importância do acaso e sabem que arte é muitas vezes mais um produto de atenção do que de intenção. $O$ processo é mais o de descoberta do que o projetual, muitas vezes. Walter de Maria já em 1961 reconhecia o potencial do randômico quando afirmava que" meaningless works potentially the most abstract, concrete, individual, foolish, indeterminate, exactly determined, varied, important art-action-experience one can undertake today". Exercício e 
tentativa de desautomatização do próprio gesto, e por consequência do olhar, o desenho cego é processo conhecido em escolas de arte, de modo que a tentativa de incluir o acaso e diminuir o potencial controle é algo conhecido e utilizado, se não como discussão aprofundada ao menos enquanto processo, no campo da arte.

Já em tecnologia, acidentes ou o acaso não são tidos como componente de absoluta importância, ainda que muitas das tecnologias atuais tiveram no acaso (ou em felizes acidentes) componentes importantes de sua elaboração e/ou melhoria evolutiva.

Ou seja, parte considerável da tecnologia atual tem em sua gênese o acaso, mas esse é um aspecto se não negado, no mínimo não comemorado. 0 randômico, como componente da maioria das linguagens computacionais, é uma ferramenta prática para parâmetros como noise, estocásticos, nos quais variáveis aleatórias são mais práticas do que delimitações de parâmetros individuais. Como comando, a tecnologia computacional claramente reconhece a importância do randômico, como estrutura de criação estocástica de parâmetros ou de criação aparentemente não simétrica de arrays, de mas penso que não o faz como processo de desenvolvimento de ideias ou de novas tecnologias de fato, ao menos não deliberadamente.

No design, disciplina projetual, problem-solver na sua origem, metas claras e previsibilidade são parte do intuito tanto do treinamento quanto do desenvolvimento tecnológico e fabril. De modo que acidentes e especulação são algo que só muito recentemente, enquanto disciplina, se leva a sério, através de conceitos como design especulativo e processos circulares. O design é disciplina que vem de pouca crítica sobre sua própria prática, de pouca especulação e de uma crença aguerrida na capacidade do projeto de solucionar problemas e encontrar respostas. Essa característica do modernismo de acreditar que dado o devido tempo e energia, todos os problemas seriam solucionados através da interferência inteligente e criativa do ser humano, é uma fábula que a grande maioria das disciplinas, reconhecendo o óbvio e as aporias, já deixou de lado; mas o design, talvez por sua origem de formação como estrutura produtiva, mercadológica, por vezes parece ainda se manter na ingenuidade da crença de seu próprio valor como instrumento genérico de solução.

A arte sempre se interessou mais sobre perguntas do que sobre respostas, enquanto campo, do que o design. A tecnologia, nesse aspecto, no meu modo de entender, tenta, a exemplo do design, ser a resposta atual para uma miríade de questões humanas, de mobilidade a política, de cidades "inteligentes" a novas moedas. De modo que por mais que o acaso seja crucial para qualquer tipo de linguagem, pouco campos o assumem com tanta tranquilidade quanto o campo da arte.

Como já notou Cauquelin, as tecnoimagens e seus desenvolvimentos, são a parte viva de fato da arte contemporânea, por que além de pesquisa de vanguarda, seguem com velocidade redefinindo exponencialmente e continuamente o campo da arte. 
Falar de tecnologia enquanto campo amplo, não só ligado a arte, é algo imenso e impreciso.Tecnologia, quando não restrita a exemplos históricos ou atuais de arte computacional, pode se referir a química ou metalurgia tanto quanto a telemática, codificação ou decodificação.

Por outro lado, arte e tecnologia têm uma história comum antiga, que começa muito antes da arte computacional. De modo que é fácil notar que existem aspectos de tecnologia tanto na pintura moderna quanto na escultura clássica, nos pigmentos e técnicas de fundição, mas nas próprias imagens, já que o desenvolvimento tecnológico criou os tornos de lentes, espelhos e vidros côncavos e convexos, que possibilitaram as câmaras lúcidas e projeções, o que mudou radicalmente a pintura no século $\mathrm{XV}$, e mais tarde a fotografia, que liberou por complete a arte de sua função representativa.

Mas tecnologia como entendemos hoje, computacional generativa é só um aspecto da enormidade que é o campo da tecnologia. Arte é outro campo não só amplo em mutação, não necessariamente evolutiva como se pretende a tecnologia, mas em redefinição constante, seja teórica, formal, poética, política ou prática. Design como disciplina definida tem criação mais recente que arte e tecnologia, e tem passado por profunda revisão teórica e crítica, incluindo aí redefinições como campo especulativo e responsabilidades em uma sociedade com preocupações e problemas de sustentabilidade e risco ambiental. Tentar aqui recortar sobre a potenciais sobreposições de campos tão amplos e fluidos de modo resumido me parece tarefa inútil, teria talvez a funcionalidade de se pretender descrever um filme a partir de um único frame.

Meu interesse aqui não é discutir tecnologia como a entendemos hoje, ou suas potencialidades ou exemplos no campo da arte e do design, mas sim imaginar como outras estruturas podem ser lidas, ou percebidas, como instrumentos de aceleração de determinado resultado, como tecnologias. Se tecnologia é um instrumento, uma alavanca para determinado fim, o que mais tem sido instrumentalizado, usado como tecnologia, e para que fim, e o que seria um instrumento especulativo importante, se pensado como tecnologia para promoção de possibilidades realmente novas.

A arte por exemplo, tem sido usada, por artistas, como uma tecnologia política, como um instrumento de tentativa mudança, ou no mínimo de protesto, em muitas poéticas. A apropriação da arte como linguagem ativista é tão corriqueira e comum que por vezes esquecemos que a crítica a realidade é tão papel da arte quanto é a crítica institucional, ou quanto a criação de realidades outras, paralelas, potenciais. Como já advertiu Benjamin, a estetização total da política é tão potencialmente catastrófica quanto a politização total da arte. A arte também é utilizada pelo capitalismo como estrutura de convencimento, como estetização de nichos e parâmetros, criação de tribos e potencialização do "pertencimento" através do consumo, fomentados pelo branding e pelo design.

LIPOVETSKY e SERROY, em A estetização do mundo utilizaram com absoluta precisão o subtítulo "Viver na era do capitalismo artista". Temos então esse uso instrumental da arte seja como protesto contra o siste- 
ma, pelos artistas, ou como ferramenta que potencializa o sistema e suas regras, pelo mercado e por seus agentes, seja como capital para relacionamento político e institucional, como relata WU, Chin-tao em Privatização da cultura. Segundo Droste, em Bauhaus, o design, que começou com a tentativa de valorizar os produtos da mecanização e da padronização, e passou por períodos de maior consciência crítica como o movimento Arts and Crafts de Morris. Como processo é, hoje, um instrumento de reposicionamento de crenças e gostos, de percepção e de criação de tendências, e muito raramente, uma disciplina especulativa de fato, e que assume sua parcela de culpa nos excessos e abusos da cadeia de consumo e problematiza sua práxis atual e futura.

Se a arte pode ser usada como tecnologia, como instrumento, ou seja, se a arte pode ter meta, ou no mínimo ser usada como linguagem em disputas mercadológicas, políticas e culturais, o que poderia ser usado como tecnologia para potencialização poética, e não prática, de resultados inesperados, da criação de novas potencialidades; talvez, imagino, a aleatoriedade. Não o "random" computacional, mas o próprio acaso, a aleatoriedade em si mesma, usada como tecnologia especulativa.

Não como comando, ou como instrumento de codificação, mas como processo investigativo de fato, como uma tecnologia da atenção a resultados inesperados e não como algo que indicasse resultados esperados, ou seja, uma tecnologia propensa não a resultados provenientes de intenção prévia, mas de geração de possibilidades, de promoção de atenção a resultados possíveis não previamente imaginados.

Aleatoriedade não necessariamente e unicamente numérica, mas semiótica, no sentido de aumentar a exponencialmente a variedade de processos de (re)construção de sentido, de desvios e novos parâmetros, de devolver algo do mistério a campos tao emaranhados com redes de certezas e familiaridade que perdem, ao menos em aspectos discursivos, parte de sua real e radical liberdade e mistério.

Ainda que partindo da tecnologia e do processamento computacional, o uso de aleatoriedade poética pode levar a resultados inesperados mesmo para aquele que cria, ou que atualiza, os dispositivos.

\section{Softwares e aleatoriedade}

Softwares são campo de intersecção entre narrativas e dispositivos poéticos ou práticos, já que, no limite, grande parte do que produzimos atualmente, em alguma de suas fases, projeto, execução, apresentação ou em sua própria forma final, é, antes de mais nada, código com uma função predefinida. No limite, temos uma narrativa codificada. Claro que assim que executada, e percebida, de algum modo, por determinado interator, ela gera um sem número de possibilidades interpretativas e, portanto, carrega em si narrativas potenciais. Mas mesmo se não chegarmos ao limite da interpretabilidade, se simplesmente lermos um código préexecução, temos ali uma narrativa codificada. 
E softwares têm outra característica: podem ser simplesmente implementados, e não originalmente programados. Ou seja, um artista utilizando linguagem codificada pode simplesmente implementar uma rotina que ele próprio não desenvolveu, ou mudá-la um pouco e ir, de algum modo, tendo uma autoria complementar. Ao mesmo tempo, essa autoria também é, assim como o código, algo consecutivo, que vai se alterando de autor em autor no caso de códigos não completamente originais.

O que permite e facilita o reúso de código são as anotações, trechos de código deliberadamente ignorados na execução do software. Por exemplo, em Processing, tudo que vem após // é ignorado pelo sistema até que a linha acabe, ou seja, até o próximo Enter.

Programadores usam essas anotações para descrever, em linguagem corrente, textual, rotinas, funções, explicações, lembretes, para que ele não tenha que reler e decifrar exatamente o código, e saiba, trecho a trecho, o que, de fato, vai acontecer, que efeito a execução daquele trecho vai produzir. Também útil na edição do código (ou no reúso), por outro programador, que copia apenas trechos que entende úteis. De fato, mesmo sem ler ou executar o código, simplesmente seguindo as anotações.

Mas o que me parece interessante aqui é que essas anotações são parte do código, de fato, estão inscritas no código, mas não são notadas por quem vê a execução do código, e também não são notadas, já que propositalmente ignoradas, pelo próprio computador, pelo sistema que executa o código. São bolhas de linguagem humana no meio da linguagem maquínica, codificada. Bolhas que são definidas de modo a passar ignoradas pelo computador e por um interator que não tenha acesso ao código. Se usadas apenas para indicações e anotações, já constituiriam leitura interessante, mas podem ser um campo da poesia ou da prosa, por exemplo, costuradas no código, invisíveis para a máquina que executa o código e para o interator que percebe e/ou interage com o resultado da execução do código.

Anotações são espaços de literatura escondida, de algo que rompe com a interação direta, mas que permite que uma mensagem seja enviada e que, mesmo assim, mesmo não codificada, compreensível, não é percebida pelo sistema que a executa nem por aqueles que testemunham sua execução. Seria percebida caso existisse, de fato, interesse pelo código em si, por aquilo que, de fato, comanda o que se pode ver/perceber/interagir. São a prova de que um interator, ainda que atualizando e recriando um dispositivo poético digital, pode estar na presença de um fantasma virtual, além daquilo que ele, de fato, percebe interagir. Algo que se aproveita do sistema e da rede para sua transmissão, mas que, ainda assim, não é lido, como código, pelo sistema que o executa.

"Cubo branco" é uma instalação multimídia para um ou quatro projetores (figuras 01-03). Preferencialmente, deve ser instalada em sala com projeções simultâneas em quatro paredes, mas o sistema pode ser apresentado em sua versão mínima, com um projetor apenas, ou em versão maquete, com um computador com microfone. 
O sistema apresenta um cubo branco, que tem seu tamanho, rotação e velocidade de repetição ditados pelo som que os interatores fazem na sala. Um computador capta o som e transmite em tempo real dados para o software, que atualiza as proporções do cubo, instantaneamente. Em silêncio total a obra simplesmente projeta um campo de luz, sem nenhuma imagem aparente.

"Cubo branco" é um trabalho em software que tenta discutir esse lugar que é o lugar da exposição, esse vazio construído, essa moldura da arte que é o cubo branco. Me interessava aí o vazio da obra sem som, e essa lógica de atualização de imagem que não parece ser criada, mas que existe em potência, e que permite ao interator criar com ela, agir com ela, e ser, de algum modo, tocado por ela, transformando o interator, enquanto na instalação, em produtor daquilo que vê. $O$ dispositivo, que é a soma da luz do projetor, do som que o interator gera e do software e do hardware que escuta e transforma essa informação, é um sistema fechado na medida em que o interator é quem percebe a obra, mas é também quem atualiza a obra, que de fato gera os sons, que, percebidos pelo sistema, geram as imagens. 
O desenho da programação tenta alterar um território já esperado, o território limpo do cubo branco, mudando a perspectiva espacial do interator em relação a uma sala ou a uma parede apenas, e, ao mesmo tempo, colocá-lo na posição de criador, de cocriador, da obra que vê e experimenta.

Essa mudança de território, tanto do vazio, quanto da atividade artística como ação exclusiva do artista, é questionada em "Cubo branco". Com luz apenas e o som ambiente, o vazio é tomado de informação, a perspectiva esperada é alterada, e o artista deixa de ser determinado ente para se transformar em função, função que em "Cubo branco" é, principalmente, realizada pelo interator.

"Cubo branco" discute o modo de exibição, o cubo branco como espaço puro, como contexto alterado pelo design, pela arquitetura, de modo a conferir um ambiente supostamente livre de influências outras e apresentar a obra sem interferências. Mas é justamente o contrário. 0 cubo branco é a interferência principal, o modo artificial que esconde, de algum modo, a realidade caótica e colabora, como moldura ou pedestal, tentando, de algum modo, autorizar algo como obra de arte.

"Cubo branco", o software, traz essa discussão projetando algo no vazio que é uma linha, que se transforma em cubo, e tem formato, escala e posição alterados pelo som gerado por quem visita a obra. Exposto no Centro Universitário Maria Antonia (figura 04), “Cubo branco" recebeu menção honrosa no Projeto Nascente 2016.

Mas "Cubo branco" tem, em seu código, a seguinte anotação, não percebida pelos interatores, pelo comitê de curadoria, e nem percebida pelo computador que executou o software: 
// Nem se eu pintasse de branco os fios e os transformadores que insistem em ficar na sua frente sem que você note, e ainda trocasse as lâmpadas dos postes por luz negra e sorrindo na sarjeta contasse a verdade até o fim, se iluminasse os bueiros com lâmpadas frias das que tiram a fome com a qual você se distrai e te fizesse ver aquilo que você faz, todo dia, aos poucos, nem assim você perceberia tudo que não vê, tudo que permite, tudo que vende barato ou dá enquanto morre sem juros, enquanto junta milhas para a viagem que você não faz e pensa se é ou não a hora de desligar os aparelhos e apertar os números, além da centrífuga um conjunto de facas convém aproveitar não costumam fazer um desconto desse tamanho quem sabe também um vaporizador entregam em pouco tempo seria ótimo, mas vamos deixar para amanhã já é tarde e uma centrífuga é sempre uma decisão séria existem muitas peças para lavar e nem se eu centrifugasse sua mão e te desse para beber enquanto todo o vapor queimasse o que sobrou dos seus olhos depois do conjunto de facas você teria a boa vontade de notar o óbvio, sua vida, se é que podemos chamar isso de trabalho, já que qualquer aparelho desses retira $60,70,80$ ou quem sabe 90 por cento dos seus afazeres e você pode aproveitar as boas coisas da vida como sua família, filhos, esposo ou esposa, a sua cara-metade, o que dá sabor a seu lar, cuidar de quem você ama, ah, que delícia, tempo para os batizados e os jantares importantes, tempo para curtir suas amizades interessantes, enquanto aparelhos maravilhosos derretem sua pele, arrancam seus olhos, liquefazem tendões e se alimentam do seu tempo que já é menor enquanto você despreza a vida que continua apostando e perdendo sem olhar seus dentes que brilham mais brancos e com um hálito incrível protegendo sua boca de vários males comuns e imperceptíveis a olho nu sim você vai adorar o branqueamento total que só quem é especialista em saúde bucal pode proporcionar consulte seu dentista e pergunte por que nem a luz negra que sai do bueiro faz com que você note enquanto sorri que são seus ossos que brilham não você, mais expostos e secos a cada dia, brancos como a sua biografia velhos como o fax que você tecla e percebe que no lugar do vaporizador convém pedir um telefone sem fio com quantas bases será que aguentam interferência temos tantos quartos todos precisam falar ao telefone teremos tomadas para tudo isso?

"Cubo branco" é um sistema cuja anotação, ou seja, aquilo que o computador não lê, é maior que o próprio código original, programado em Processing por mim, e é um exemplo de como anotações podem, eventualmente, criar uma literatura paralela que, apesar de não percebida, está lá e faz parte da obra, ou, no mínimo, de um aspecto real, funcional, da obra. Parte não codificada, anotada, do código de "Cubo branco". 
Essa segunda camada de discussão é, de fato, tão importante quanto a primeira, já que a discussão, de fato, em "Cubo branco" é o sistema da arte, aquilo que autoriza algo a ser uma obra, o circuito que apresenta e valida mesmo sem perceber sua complexidade.

Ou seja, "Cubo branco", o software, recebeu menção honrosa sendo percebido, validado, de algum modo, por público e pela curadoria, somente em parte daquilo que de fato é, já que parte do corpo da obra não foi sequer percebido, notado ou verificado, como era de se esperar.

Nem o computador, nem a curadoria, nem o público, percebem parte crítica de "Cubo branco". Distraídos com a funcionalidade do sistema, perdem parte da informação da obra, já que são impactados e reagem a ela do modo que compreendem. Interagem no espaço que parece potencialmente interativo, e só. A aleatoriedade de cubo branco era formal, mas a crítica permanecia codificada.

"Cubo branco" tem algo de provável, físico, em seu código que, no entanto, não é percebido quando a obra é apresentada, nem pelos interatores, nem pelos curadores, nem pelo computador que permite ao sistema rodar.

Obra que é parte sigilo, parte código e parte interação, "Cubo branco" é, de algum modo, retrato de nosso tempo, seguimos distraídos com a tecnologia e com o volume de informação sem perceber camadas mais profundas daquilo com o que entramos em embate.

O aleatório em cubo branco não é só a geração da imagem, que processa e se altera de modo randômico em relação ao som da sala, mas a própria aleatoriedade com que os interatores e curadores interagem com a projeção, percebendo sua cocriação mas ignorando camadas críticas daquilo com o que interagem.

Fig 4. Instalação multimídia "Cubo branco" no Maria Antonia Fonte: Criação própria, Cubo branco (2016).

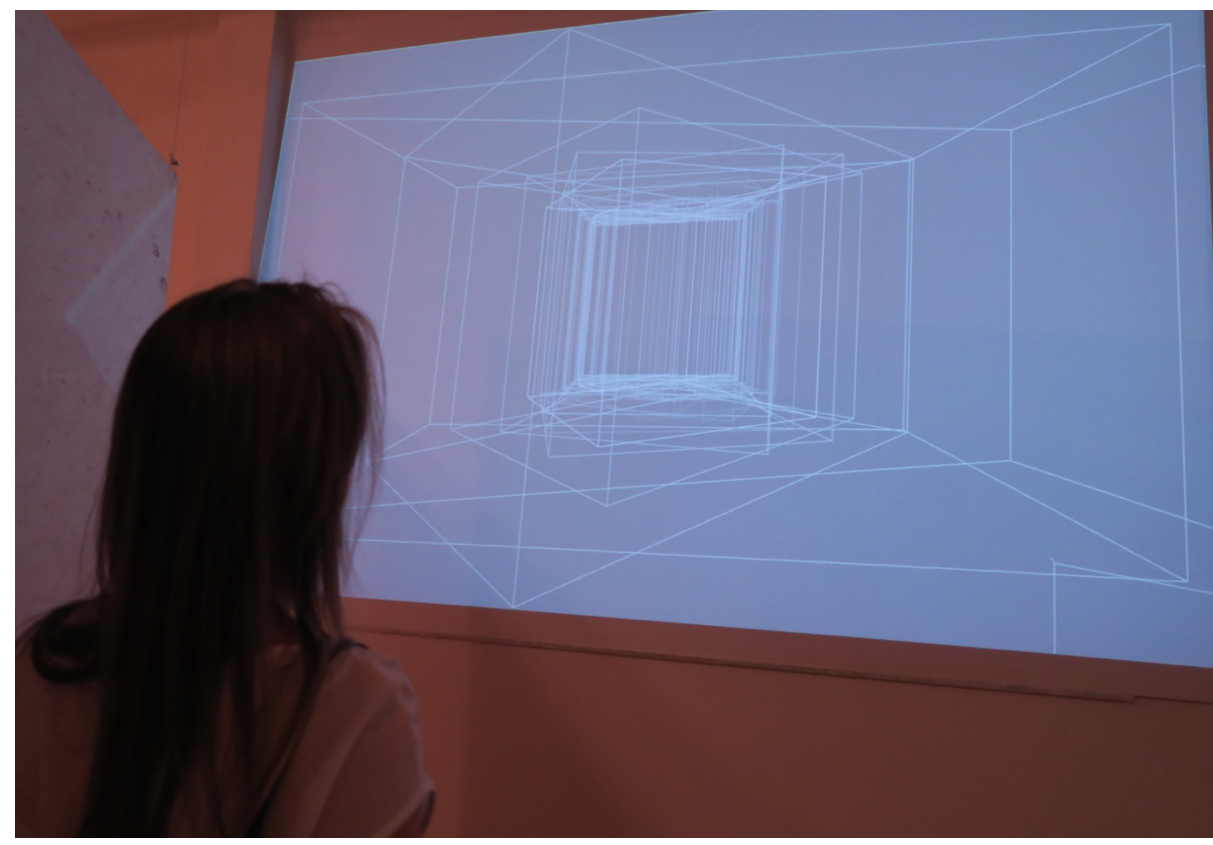


0 randômico como instrumento na arte e no design.

\section{Dispositivos especulativos e catalisadores de aleatoriedade}

Trabalhando nas sobreposições de processos lógicos e projetuais de design/práxis, linguagem/narrativa e arte/poética, qual seria a possibilidade metodológica do processo criativo usando a aleatoriedade como tecnologia semiótica, como instrumento especulativo. Seria possível criar com a ajuda de um processo metodológico e, ainda assim, criar algo de fato inesperado inclusive para quem cria?

É possível parametrizar o acaso? De fato, e não alegoricamente?

Como dispositivo poético, temos exemplos. Talvez o mais célebre desses exemplos seja de Marcel Duchamp, "Trois stoppages étalon" "Three standard stoppages"), obra de 1913 (figuras 05-07). "Trois stoppages" são réguas para repetir o acaso. Nenhuma delas tem um metro, ao mesmo tempo em que todas têm um metro. Nenhuma é como a outra. Mas todas são produzidas da mesma e exata maneira. Ou seja, Duchamp produziu um paradoxo. Um paradoxo que é uma tentativa irônica de se parametrizar o acaso. Duchamp repetiu três vezes o mesmo processo com três fios idênticos de 1 metro de comprimento, Deixando o fio cair desde 1 metro de altura, Duchamp fixava a posição exata do fio quando atingia um feltro sobre o chão. Depois, recortou em madeira réguas da exata curvatura das linhas. $\mathrm{E}$ apresentou o conjunto (a prova do processo, três linhas coladas em feltros, colados em placas de vidro, mais as três réguas que parametrizavam os metros caóticos), em uma caixa. Essa era a obra, o paradoxo e a ironia de se parametrizar o acaso. De fato, ironia, mas, ao mesmo tempo, possível, real, existente como possibilidade, pós-construção do dispositivo.
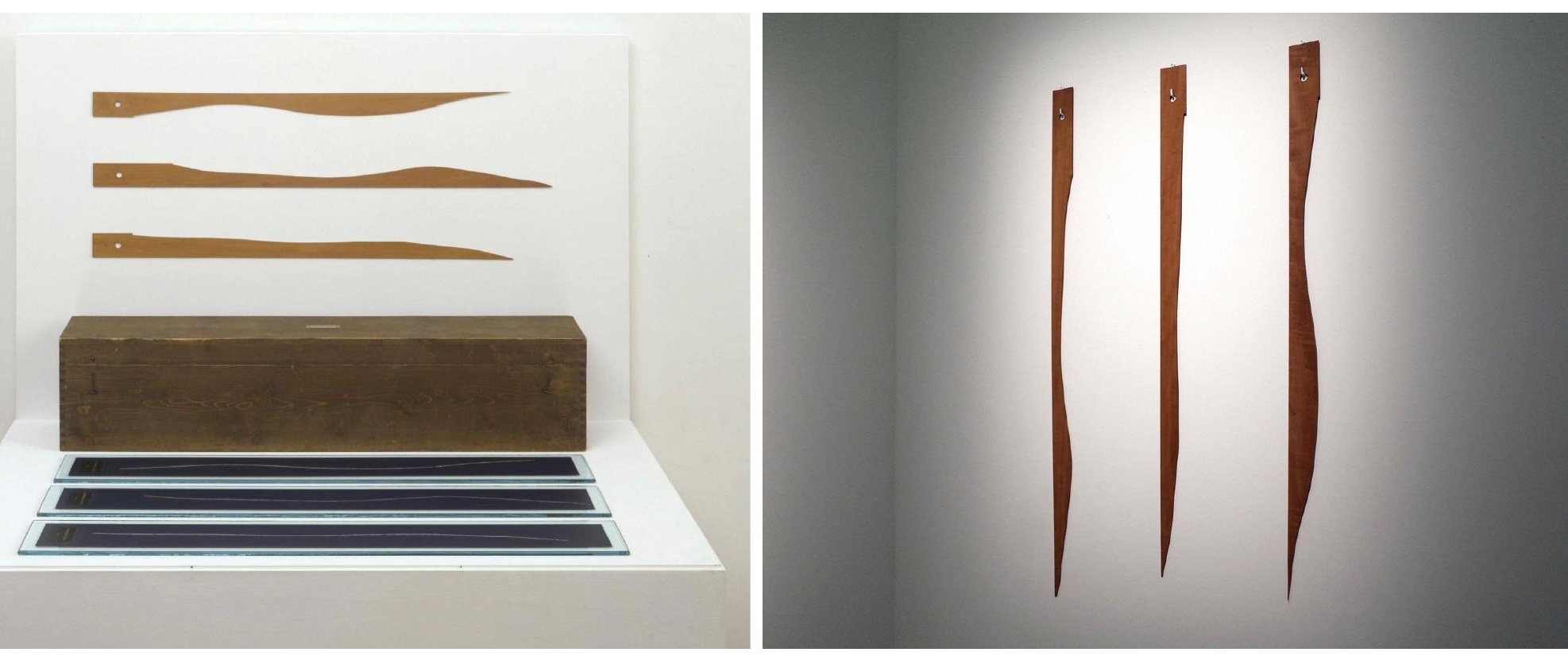

Figs 5 e 6. Obra "Trois stoppages étalon" de Marcel Duchamp

Fonte: Marcel Duchamp, Trois stoppages étalon (1913). 


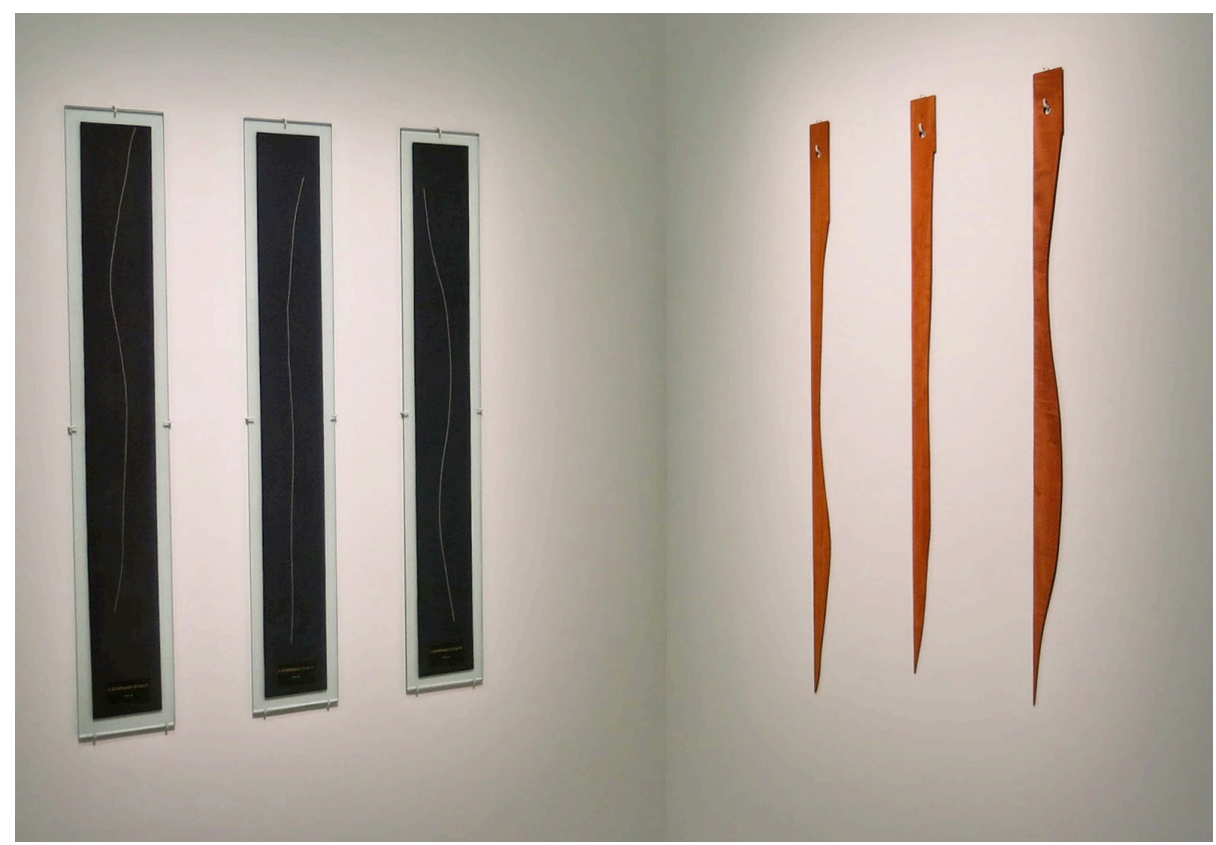

Fig 7. Obra "Trois stoppages étalon" de Marcel Duchamp

Fonte: Marcel Duchamp, Trois stoppages étalon (1913).

Qualquer metodologia ou processo que permita encontrar novos insights ou potencialidades criativas de fato novas deve necessariamente permitir, e talvez promover o acaso, de algum modo.

De modo que são, assim como martelos, computadores, grampeadores, pincéis, ferramentas criativas. Mas ferramentas sistêmicas, lógicas, que permitem algum modo conhecido, replicável, de se chegar a resultados ainda desconhecidos, por caminhos não replicáveis nem esperados.

Artistas usam ferramentas práticas e poéticas, lógicas e processuais, assim como designers, arquitetos, escritores. Temos exemplos históricos, e o próprio uso de softwares e linguagens preestabelecidas é, de algum modo, prova de que trabalhamos a partir de parâmetros, que quando acumulados parecem aleatórios, randômicos, mas não são, de fato. O Verbasizer é um software de recombinação de letras criado (e utilizado frequentemente) por David Bowie. Matthew Braga escreve no canal Motherboard, da Vice on-line ${ }^{1}$ :

One of my favourite videos of David Bowie (I have a few) is a clip from the 1997 documentary Inspirations, directed by Michael Apted. Filmed during the production of Bowie's 1995 album Outside, Bowie is sitting at a black Apple PowerBook, in front of a sentence randomizer app he designed for writing the album's lyrics.

Bowie gestures to the screen: "It's a program that I've developed with a friend of mine from San Francisco, and it's called the Verbasizer."

Demonstrating the program, he continues. "It'll take the sentence, and 
I'll divide it up between the columns, and then when I've got say, three or four or five - sometimes I'll go as much as 20,25 different sentences going across here, and then I'll set it to randomize. And it'll take those 20 sentences and cut in between them all the time, picking out, choosing different words from different columns, and from different rows of sentences."

"So what you end up with is a real kaleidoscope of meanings and topic and nouns and verbs all sort of slamming into each other."

-...

The Verbasizer was a digital version of an approach to lyrical writing that Bowie had been using for decades, called the cut-up technique. Popularized by writers William Burroughs and Brion Gysin, the technique relied on source literary material - a newspaper article or diary entry, perhaps - that had been cut up into words or phrases, and re-ordered into new, random, potentially significant meanings.

In typical Bowie fashion, he had reinvented the technique, albeit with a digital twist.

Verbasizer é uma estrutura que adiciona um padrão randômico (uma tentativa de se imitar o acaso) em uma série de palavras. Era usado como acelerador criativo por Bowie em seu trabalho como letrista.

A questão é que, ainda se encararmos a música de Bowie como arte, e não como produção da indústria musical, mas se encararmos como um trabalho autoral de um artista, Bowie sabia, quando começava uma letra, que fazia uma música. 0 Verbasizer não permitia que o artista seguisse no processo, mas terminasse produzindo o design de uma cadeira ou um programa de TV. O software servia a um processo que ainda que fosse poético, em sua origem, era prático no sentido de que tinha pauta, alvo final. Essa estrutura não tirava a autoria de Bowie, nem parece ter feito o artista se repetir. Na verdade, essa estrutura servia como acelerador, como potencializador de acasos, e, dentre as possibilidades, o artista fazia suas escolhas.

Esse embate entre o novo e o que está pré-programado é, de fato, embate em parte dos casos, mas em processos criativos isso me parece mais uma colaboração de dois modos de agir (dúvida e meta, risco e pauta, acaso e desejo, intenção e atenção), e essa colaboração, esse jogo, acaba por acelerar e facilitar o processo criativo. A poesia automática dos dadaístas Tzara e Breton, por exemplo, é possivelmente o ato poético original que deu origem ao Verbasizer. Mas o uso que Bowie fez do processo é distinto, é menos obediente pós-processo, já que Bowie, deliberadamente, pós-input do sistema e verificação de possibilidades, escolhia a que lhe parecia fazer mais sentido. Mas é importante o fato de que Bowie, enquanto artista radicalmente criativo, seja musicalmente ou em outras áreas, como pintor, figurinista, designer de imagens e de performances, entendia que metodologias são apenas ferramentas, estruturas que facilitam, aceleram ou diversificam um processo, que não deixa de ser criativo pelo uso dessas mesmas ferramentas. 
Meu interesse por geradores de aleatoriedade lógica, poética e prática tem me levado a tentativas de formatar não lógicas, mas processos abdutivos catalisados de algum modo. Em 4 de junho de 2016 apresentei em Tallinn, na Estônia, no Semiofest 2016, congresso de semiótica aplicada e produção de metapensamento semiótico, cujo tema do ano era inovação, uma metodologia abdutiva, uma estrutura catalisadora para produção de insights. Estrutura conceitual, próxima de um jogo, que acelera a criação de caminhos potenciais, aleatórios. Infuse é uma máquina geradora de micro-obstáculos, ou parâmetros combinatórios, que, de algum modo, permitem um pensamento criativo prático acelerado. Não serve ao propósito de se criar dispositivos poéticos, ou processos poéticos, mas é ferramenta útil para criadores com metas, ou seja, para quem tem pautas, projetos e, grande parte das vezes, prazos. Infuse, em si, por outro lado, é um ato poético, uma tentativa de descobrir e testar algo novo, que é, de fato, uma metodologia para o acaso, para o descobrimento de caminhos alternativos. Mas uma vez pronto, se utilizado, é um método, especulativo, entre tantos, para criadores práticos. Desenvolvi essa metodologia como parte do meu trabalho, como uma camada adicional, randômica, que eu pudesse usar como alternativa aos meus processos; ao mesmo tempo, criar a ferramenta em si foi um trabalho caótico, inicialmente sem meta, que mistura risco, acasos e pautas.

Infuse também foi apresentado individualmente a profissionais criativos e segue sendo testado, por criativos que se interessaram ou, por algum motivo, resolveram colaborar com a fase seguinte da pesquisa, que é descobrir se Infuse, de fato, funciona para outros criativos, e de que modo funciona. Surgiu do acúmulo de possibilidades e processos e, só no final, se transformou em metodologia.

Tentativa de criar um mapa para qualquer direção, jamais definitivo, e jamais único. Infuse é, de fato, algo próximo de uma máquina de acasos, não numéricos, mas conceituais. Uma estrutura para possibilidades alternativas, potenciais. Funciona como um jogo cujo fim é a produção de possibilidades conceituais não imaginadas por quem joga.

Parece-me ser, no mínimo, prova de que processos transmissíveis podem colaborar com processos criativos de várias naturezas. Talvez nosso preconceito com métodos criativos lógicos, seja o mesmo preconceito original do movimento "Arts and Crafts", do artesão ser substituído pela máquina, mesmo que a máquina, nesse caso, seja um aparato lógico.

Como já notou Monica Tavares, os processos criativos podem, de fato, ser derivados de práticas que são, se percebidas em profundidade, industriais:

Nevertheless, it was the characteristic of the montage, collage, and bricolage procedures deriving from industrial assembly that inaugurated the reproductive operations of destructuring and restructuring. From those practices, the universes of originals and reproductions, in addition to maintaining parallelism and autonomy, also interpenetrate and 
0 randômico como instrumento na arte e no design.

semanticize each other. The industrial process, being essentially scientific, analyzes the model in parts aimed at its synthetic reconstitution, therefore allowing us to speak of a language process, in which paradigm and syntagma work together. Thus, the interchange between the parts montage, collage, and bricolage - is a creative process deriving from the industrial assembly line. (TAVARES, 2015, p. 192-203)

Penso que assim como estruturas codificadas, e programadas, estruturas lógicas, se usadas criativamente, são instrumentos e podem funcionar como linguagem, assunto, metodologia, ferramental, ou podem, no limite, ser usados como experiências criativas atípicas, como pontos de partida poéticos, ou como novas direções, inesperadas, em processos práticos.

1 VER http://motherboard.vice.com/read/the-verbasizer-was-david-bowies-1995-lyric-writing-mac-app

\section{Referências}

AGAMBEN, Giorgio. 0 homem sem conteúdo. São Paulo: Autêntica Editora, 2012. p. 207. AGAMBEN, Giorgio. O que é o contemporâneo? e outros ensaios. Chapecó: Argos Editora da Unichapecó, 2013. p. 92.

AGAMBEN, Giorgio. Estâncias: a palavra e o fantasma na cultura ocidental. Belo Horizonte: Editora UFMG, 2012. p. 263.

AGAMBEN, Giorgio. 0 que é um dispositivo? Tradução: Nilceia Valdati. Fala proferida por Giorgio Agamben em conferência realizada no Brasil, em setembro de 2005 . A tradução foi feita a partir do original em italiano. (N.T.) IIha de Santa Catarina - $2^{\circ}$ semestre de 2005. ALBERRO, Alexander; STIMSON, Blake. Institutional critique. Cambridge: The MIT Press, 2011. p. 492.

BARROS, Manoel de. Livro sobre nada. Rio de Janeiro: Editora Record, 2009. p. 85.

BAUMAN, Zygmunt. A moralidade na perspectiva moderna e pós-moderna. In: Ética pós-moderna. São Paulo: Paulus, 1997.

BELTING, Hans. Likeness and presence. Paperback ed. Chicago: The University of Chicago Press, 1996. p. 651.

BELTING, Hans.o fim da história da arte. 1. ed. São Paulo: Cosac Naify, 2005. p. 320. 
0 randômico como instrumento na arte e no design.

BENJAMIN, Walter. A obra de arte na era de sua reprodutibilidade técnica. In: Obras escolhidas: Magia e técnica, arte e política. São Paulo: Brasiliense, 1996. p. 254.

BERMAN, Marshall. O modernismo nas ruas. In: Tudo que é sólido desmancha no ar. A aventura da modernidade. São Paulo: Companhia das letras, 1997. p. 129-144.

BERMAN, Marshall. Tudo que é sólido desmancha no ar. São Paulo: Companhia das letras, 2007. p. 465.

BIRKETT, Whitney B. To infinity and beyond: a critique of the aesthetic white cube. Submitted in partial fulfillment of the requirements for the degree of Master of Arts in Museum Professions. Seton Hall University, May 2012. p. 83.

BOHNACKER, Hartmut et al. Generative design. New York: Princeton Architectural Press, 2012. p. 477.

BRAGA, Matthew. The Verbasizer was David Bowie's 1995 Lyric-Writing Mac App. ON-LINE: http://motherboard.vice.com/read/the-verbasizer-was-david-bowies-1995-lyric-writing-mac-app, Vice Media, 2016.

BUSKIRK, Martha. The contingent object of contemporary art. Cambridge: The MIT Press, 2005. p. 307.

Cabral, Artur; Venturelli, Suzete; Prado, Gilbertto. Sinais detectados entre o biológico e o maquínico . DATJournal V4, N. 3 (2019), p. 117-127. Disponível em: < https://datjournal. anhembi.br/dat/article/view/152/130>. Acesso em 15 de março de 2020. DOI: https://doi. org/10.29147/dat.v4i3.152

CARDOSO, Rafael. Design para um mundo complexo. São Paulo: Cosac Naify, 2014. p. 262. CAUQUELIN, Anne. Arte contemporânea. Uma introdução. São Paulo: Martins Editora, 2005. p. 165.

Teorias da arte. São Paulo: Martins Editora, 2005. p. 177.

COLES, Alex. Design and art. London/Cambridge: Whitechapel Gallery and The MIT Press, 2007. p. 208.

DANTO, Arthur C. A transfiguração do lugar-comum. Uma filosofia da arte. 1. ed. São Paulo: Cosac Naify, 2005. p. 312.

DANTO, Arthur C. Após o fim da arte. A arte contemporânea e os limites da história. 1. ed. São Paulo: Edusp, 2006. p. 292.

DANTO, Arthur C. Andy Warhol: Arthur C. Danto. São Paulo: Cosac Naify, 2012. p. 205.

DROSTE, Magdalena. Bauhaus. Köln: Taschen, 2004. p. 256.

DUNNE, Anthony; RABY, Fiona. Speculative everything. Cambridge: The MIT Press, 2013. p. 224.

ELLENBERG, Jordan. How not to be wrong. New York: Penguin Press, 2014. p. 468.

FARIAS, Agnaldo. Design é arte?(1) In: Vitruvius 006.06 ano 01, nov. 2000, p. 3. arquitextos ISSN 1809-6298.

FLUSSER, Vilém. A filosofia da caixa preta. São Paulo: Relume Dumará, 2002. p. 82.

FLUSSER, Vilém. 0 mundo codificado. São Paulo: Cosac Naify, 2007. p. 224.

FURTADO, José Luiz. A arte e as dimensões recalcadas da sensibilidade na existência cotidiana. $13 \mathrm{p}$.

GRAHAM, Beryl; COOK, Sarah. Rethinking curating after new media. Cambridge/London: The MIT Press, 2010. p. 354.

HYDE, Lewis. Trickster makes this world. Mischief, myth and art. New York: Farrar, Strauss and Giroux, 2010. p. 417. 
IVERSEN, Margaret. Chance. London/Cambridge: Whitechapel Gallery and The MIT Press, 2010. p. 238.

ITO, Joichi. Can design advance science, and can science advance design? ON-LINE: http://jods.mitpress.mit.edu/pub/designandscience. p.9.

KLANTEN, Robert et al. Art \& agenda: Political art and activism. Berlin: Gestalten, 2011. p. 288. KRAUSS, Rosalynd E. The originality of the avant-garde and other modernist myths. Cambridge/London: The MIT Press, 1986. p. 307.

LE FEUVRE, Lisa. Failure. London/Cambridge: Whitechapel Gallery and The MIT Press, 2010. p. 238 .

LIMA, Gercina A. B. (2007). Categorização como um processo cognitivo. Ciências \& Cognição. Ano 04. Vol. 11. p. 156-167. Disponível em www.cienciasecognicao.org.

LIPOVETSKY, Gilles; SERROY, Jean. A estetização do mundo. Viver na era do capitalismo artista. São Paulo: Companhia das letras, 2015. p. 467.

MANOVICH, Lev. The language of new media. Cambridge: The MIT Press, 2001. p. 354.

MARZONA, Daniel. Arte conceptual. Colônia: Taschen, 2007. p. 96.

MCCRACKEN, Grant. Cultura e consumo. Rio de Janeiro: Mauad editora. p. 205.

MCCRACKEN, Grant. Cultura e consumo II. Rio de Janeiro: Mauad editora. p. 203.

MCCRACKEN, Grant. Culturematic. Boston: Harvard Business Review Press, 2012. p. 291.

MONTERROSO, Augusto. A ovelha negra e outras fábulas. Coimbra: Angelus Novus, 2008.

p. 117.

MUNARI, Bruno. Design as art. London: Penguin Books, 2008. p. 223.

NAVAS, Eduardo. The new aesthetic and the framework of culture. Media-N. Journal of the New Media Caucus. v.08 n.02. Disponível em http://median.s151960.gridserver. com/?page_id=93. Acesso em: 15 de março de 2015.

NAVAS, Eduardo. http://remixtheory.net/?page_id=3.

O'DOHERTY, Brian. Inside the white cube: the ideology of the gallery space. Berkeley and Los Angeles: University of California Press, 1999.

O'NEILL, Paul. The culture of curating and the curating of culture(s). Cambridge: The MIT Press, 2012. p. 180.

OXMAN, Neri. Age of entanglement. An inaugural essay for the Journal of Design and Science (JoDS). ON-LINE: http://jods.mitpress.mit.edu/pub/AgeOfEntanglement.

PAREYSON, Luigi. Os problemas da estética. São Paulo: Martins Fontes, 2001. p. 246.

PAZ, Octavio. Signos em rotação. São Paulo: Editora Perspectiva, 2012. p. 316.

PAZ, Octavio. Marcel Duchamp ou o castelo da pureza. São Paulo: Editora Perspectiva, 2014. p. 103. PEIRCE, Charles Sanders. Semiótica. São Paulo: Editora Perspectiva, 2008. p. 337.

PEIRCE, Charles Sanders.Collected papers of Charles Sanders Peirce, Volumes I, II, III, IV, V and VI, 1931-1935.

PETRY, Michael. The art of not making. New York: Thames \& Hudson, 2011. p. 208. PLAZA, Julio. Tradução intersemiótica. São Paulo: Editora Perspectiva, 2010. p. 217.

PLAZA, Julio; TAVARES, Monica. Os métodos heurísticos de criação. In: Processos criativos com os meios eletrônicos: poéticas digitais. São Paulo: Hucitec, 1998.

PRADO, Gilbertto.; VALENTE, Agnus; Carramaschi, Ana Elisa; Thomaz, Andrei; Lima, Leonardo; Ohira, Luciana; Trentin, Maurício; Germano, Nardo; Bonilha, Sérgio. Algunos apuntes sobre la relectura y el siempre rehacer de algunas obras. In Prado, Gilbertto; La Ferla, Jorge (Org.). Circuito Alameda. Ciudad de México: Instituto Nacional de Bellas Artes | Laboratorio Arte Alameda, 2018. p. 38-52. 
PRADO, Gilbertto. Arte telemática: dos intercâmbios pontuais aos ambientes virtuais multiusuário. São Paulo: Itaú Cultural, 2003.

PRADO, Gilbertto; TAVARES, Monica; ARANTES, Priscila (Org.). Diálogos transdisciplinares: arte e pesquisa. São Paulo : ECA/USP, 2016. Disponível em: <http://www.poeticasdigitais.net/assets/dialogostransdisciplinares2.pdf Acesso em 10 de março de 2019.

SANTAELLA, Lucia. Semiótica aplicada. São Paulo: Thompson, 2007. p. 186.

SCOVINO, Felipe. Encontros | Cildo Meireles. Rio de Janeiro: Beco do Azougue, 2009. p. 293. SOMERSON, Rosanne; HERMANO, Mara L. The art of critical making. New Jersey: Wiley, 2013. p. 272.

STILES, Kristine; SELZ, Peter (Editors). Theories and documents of contemporary art. Berkeley: University of California Press, 1996. p. 1003.

STOLARSKI, André. Design e arte: campo minado. São Paulo: Dissertação (Mestrado - Área de Concentração: Projeto, Espaço e Cultura) FAUUSP, 2012. p. 255.

STOLARSKI, André. Digital poetics and remix culture: from the artisanal image to the immaterial image. In: Navas, Eduardo; Gallagher, Owen; burrough, xtine (eds). The Routledge Companion to Remix Studies. New York and London: Routledge, 2015. p. 192-203.

STOLARSKI, André. Os processos criativos com os meios eletrônicos. Dissertação apresentada ao Curso de Mestrado em Multimeios do Instituto de Artes da UNICAMP. CAMPINAS: UNICAMP, 1995. p. 183.

TOMKINS, Calvin. Duchamp. 1 ed. São Paulo: Cosac Naify, 2005. p. 583.

TOMKINS, Calvin. Marcel Duchamp. The afternoon interviews. New York: Badlands unlimited, 2013. p. 97.

TRENTIN, Maurício. Possibilidades comunicacionais e relacionais entre obras de arte e seus intérpretes como base para categorização da produção contemporânea. São Paulo: COS-PUCSP, 2010. p. 154.

WESCHELER, Lawrence. Seeing is forgetting the name of the thing one sees. Berkley and Los Angeles: University of California Press, 2008. p. 310. 